\title{
Bilateral obstetric brachial plexus paralysis: a case report
}

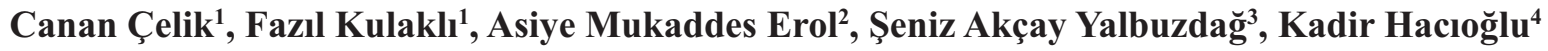 \\ ${ }^{1}$ Department of Physical Medicine and Rehabilitation, Giresun University School of Medicine, Giresun, Turkey \\ ${ }^{2}$ Department of Physical Medicine and Rehabilitation, Bursa Yüksek Ihtisas Training and Research Hospital, Bursa, Turkey \\ ${ }^{3}$ Department of Physical Medicine and Rehabilitation, Bozyaka Training and Research Hospital, Izmir, Turkey \\ ${ }^{4}$ Department of Physical Medicine and Rehabilitation, Sultan 1. Murat State Hospital, Edirne, Turkey
}

DOI: $10.18621 /$ eurj.376344

\begin{abstract}
We aim to report a case with bilateral obstetric brachial plexus paralysis rarely seen after cesarean section. A 28-month-old girl was admitted to our outpatient clinic with weakness in both upper extremities. Shoulders were adducted and internally rotated, elbows were extended with flexion fingers. The 37-year-old mother, fetal breech presentation, premature birth and probably traction forces applied at birth were considered among the risk factors. With this case, it is emphasized that obstetric brachial plexus paralysis occurs rarely bilateral and after cesarean section.
\end{abstract}

Keywords: Bilateral brachial plexus palsy, infant, cesarean, obstetrics

Received: January 8, 2018; Accepted: February 2, 2018; Published Online: February 13, 2018

$\mathrm{O}^{\mathrm{h}}$ bstetrical brachial plexus injury is defined as a flaccid paresis of an upper extremity due to brachial plexus injury at birth [1]. The incidence varies between 1 and 1.5 per 1000 live births [2]. Hardy [3] reported that five percent of obstetric brachial plexus palsies are bilateral. We aim to report a case with bilateral obstetric brachial plexus paralysis rarely seen after cesarean section.

\section{CASE PRESENTATION}

A 28-month-old girl, was admitted to our outpatient clinic with weakness in both upper extremities. Her mother was 37 years old when had given birth. She had received $15 \mathrm{~kg}$ during pregnancy and she was $75 \mathrm{~kg}$ at birth. There was no uterine anomaly. At $36^{\text {th }}$ weeks with breech presentation, she had given birth by cesarean section under general anesthesia. The infant weighed $2.5 \mathrm{~kg}$ and heightened $47 \mathrm{~cm}$ at birth. According to Gilbert Shoulder Scale right upper extremity was 1 and left was 0 , and according to Mallet's Scale right extremity was 2 and left was 1 [4]. Her proximal muscles of upper extremities were atrophic. Shoulders were adducted and internally rotated, elbows were extended with flexion fingers ("waiter's tip" [1]) (Figure 1).

Cranial, cervical magnetic resonance imaging, and electroencephalography were normal. Evaluated bilateral upper extremity nerve conduction studies and electromyography examination were consistent with moderate neuropathy characterized by axonal degeneration in the bilateral upper-middle-lower trunk.

The rehabilitation program consists of the gently passive range of motion exercises, supporting of joints

Address for correspondence: Fazll Kulakl, MD., Assistant Professor, Giresun University School of Medicine, Department of Physical Medicine and Rehabilitation, Giresun, Turkey.

E-mail:drfzl46@gmail.com 


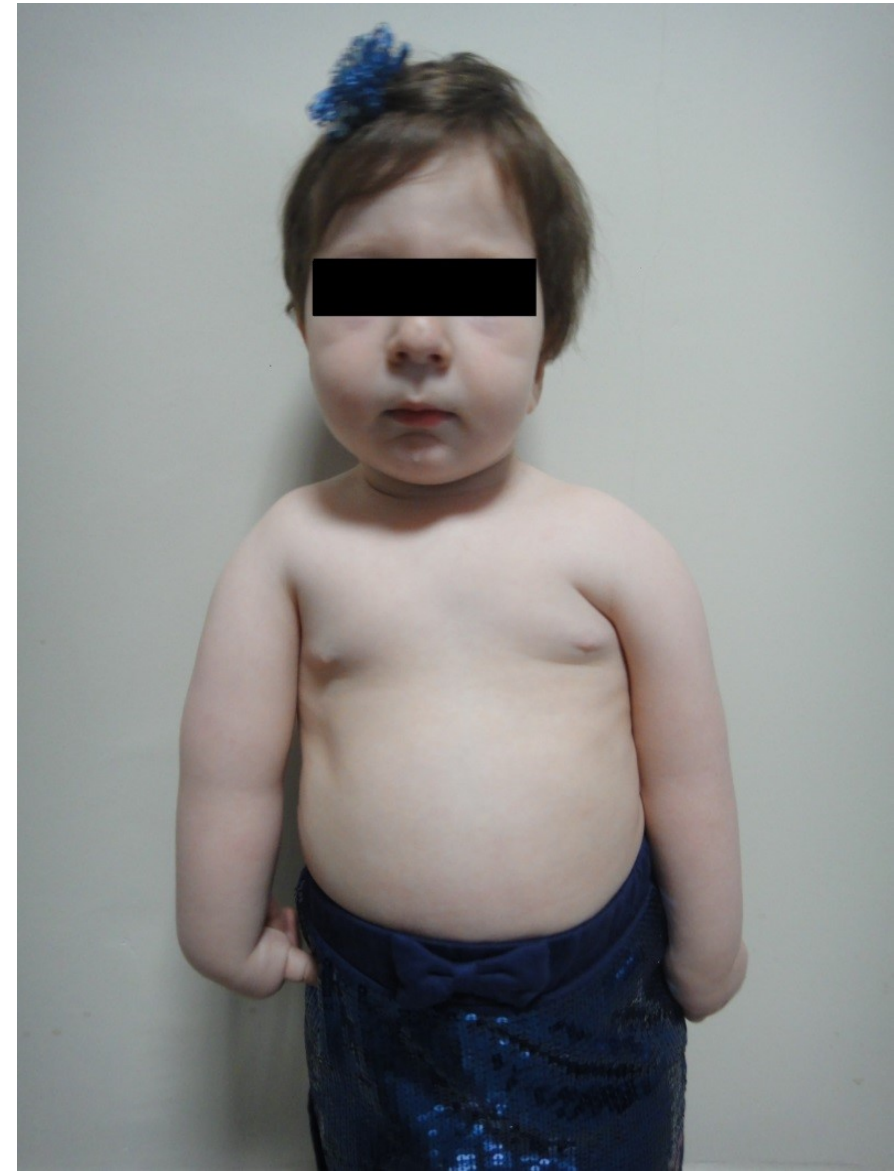

Figure 1. Bilateral adducted shoulders and extended elbows and atrophic proximal muscles were seen ("waiter's tip").

and proper positioning, active assistive exercises and stretching muscle groups to prevent contractures have performed.

An informed consent form was signed by the parents of the patient to approve the use of patient information or material for scientific purposes.

\section{DISCUSSION}

Obstetric brachial plexus palsy is a serious problem in infancy that can be prevented. Although $70-92 \%$ of patients can able to return to normal function, some patients result in prolonged and persistent disability [1]. Hardy [3] and Dragu et al. [5] indicated that bilateral cases represent a more severe condition than unilateral cases.

Neonatal brachial plexus may be damaged by being stretched, compressed, infiltrated, or deprived of oxygen. Stretch is the most common responsible mechanism. Predisposing factors include maternal causes (of greater than 35 maternal age, diabetes mellitus, excessive weight gain during pregnancy, obesity, primiparity), factors associated with labor (shoulder dystocia, breech presentation, instrumented delivery, epidural anesthesia, shortness of second stage of labor) and fetal factors (macrosomia $>4 \mathrm{~kg}$, decreased fetal arm movements, the presence of a first cervical rib and clavicle fracture) $[1,2,5,6]$. Brachial injury occurs more frequently with breech deliveries, which are usually combined with low birth weight [1]. Maternal older age (37 years old), fetal breech presentation, and premature birth can be considered as the risk factors in our case.

The risk of an obstetrical brachial plexus palsy is lower with cesarean section than with vaginal delivery $[1,6]$. The actual incidence of birth palsy in newborns delivered by cesarean section is unknown [7]. AlQuattan et al. [7] demonstrated that only 1\% of 1561 newborns with obstetrical brachial plexus injury were delivered by cesarean section.

It has been reported that the cases of obstetric brachial palsy in cesarean sections occur as a result of forceful traction and manipulation by the obstetrician [1]. Besides the importance of traction, the interaction of the physical strength to oppose the forces (brachial plexus nerve bundle, shoulder muscles, bone structure) also plays a significant role. Spontaneous or induced uterine contractions as a driving force can contribute to the traction forces. Some researchers believe that intrauterine maladaptation is responsible for the brachial plexus palsy when considering there are not significant traction forces during the implementation of the suspect or a proven cause at the birth $[2,5]$. We think the existence of a possible traction and manipulation forces during the cesarean section in our case.

Bilateral lesions are often associated with breech presentations and are reported in $0-23 \%$ of all cases [1]. Dragu et al. [5] reported a case with bilateral obstetric brachial plexus lesions and low birth weight (800 g), indicated that this case is very rare. Baliarsing et al. [8] reported that a case with bilateral obstetric brachial plexus injury affected C5 and C6 nerve roots. This patient had been born at full term by vertex 
presentation. Unlike the cases reported, there was a breech presentation in our case, and birth was carried out by cesarean section, not vaginal. We did not find bilateral obstetric brachial plexus palsy after cesarean section in the literature similar to our case.

\section{CONCLUSION}

Bilateral obstetric brachial plexus paralysis is very rare incidence in infants. We consider that maternal older age, fetal breech presentation, premature birth and probably traction and manipulation forces applied at cesarean section are among the risk factors. As a result of the case, it is emphasized that obstetric brachial plexus paralysis occurs rarely bilateral and after cesarean section.

\section{Informed consent}

Written informed consent was obtained from the patient's parents for the publication of this case report.

\section{Conflict of interest}

The authors declared that there are no potential conflicts of interest with respect to the research, authorship, and/or publication of this article.

\section{REFERENCES}

[1] Zafeiriou DI, Psychogiou K. Obstetrical brachial plexus palsy. Pediatr Neurol 2008;38:235-42.

[2] Alfonso DT. Causes of neonatal brachial plexus palsy. Bull NYU Hosp Jt Dis 2011;69:11-6.

[3] Hardy AE. Birth injuries of the brachial plexus: incidence and prognosis. J Bone Joint Surg Br 1981;63:98-101.

[4] Vergara-Amador E. Latissimus dorsi transposition for sequelae of obstetric palsy. Colomb Med 2010;41:248-55.

[5] Dragu A, Horch RE, Wirth S, Ingianni G. Bilateral obstetric brachial plexus paralysis: a case report. Klin Padiatr 2009;221:57-9.

[6] Ouzounian JG. Risk factors for neonatal brachial plexus palsy. Semin Perinatol 2014;38:219-21.

[7] al-Qattan MM, el-Sayed AA, al-Kharfy TM, al-Jurayyan NA. Obstetrical brachial plexus injury in newborn babies delivered by caesarean section. J Hand Surg Br 1996;21:263-5.

[8] Baliarsing AS, Doi K, Hattori Y. Bilateral elbow flexion reconstruction with functioning free muscle transfer for obstetric brachial plexus palsy. J Hand Surg Br 2002;27:484-6. 